\title{
Maternal Sensitive Determinants of Nutritional Status Among Children Below Five Years in Obunga Slums
}

\author{
David Omondi Okeyo ${ }^{1,}$, Peter Kirabira ${ }^{2}$ \\ ${ }^{1}$ School of Public Health, Department of Nutrition and Health, Maseno University, Maseno Township, Kenya \\ ${ }^{2}$ Institute of Public Health and Management, International Health Sciences University, Kampala, Uganda
}

Email address:

jandigwa@yahoo.co.uk (D. O. Okeyo),pkirabira@ihsu.ac.ug (P. Kirabira)

${ }^{*}$ Corresponding author

\section{To cite this article:}

David Omondi Okeyo, Peter Kirabira. Maternal Sensitive Determinants of Nutritional Status Among Children Below Five Years in Obunga Slums. Science Journal of Public Health. Vol. 4, No. 3, 2016, pp. 265-270. doi: 10.11648/j.sjph.20160403.26

Received: May 1, 2016; Accepted: May 11, 2016; Published: May 27, 2016

\begin{abstract}
Malnutrition remains a major proxy determinant of child mortality common among under five children and account for about one-third of malnourished cases worldwide. This chronic condition is a severe public health problem in subSaharan Africa that requires continuous critical attention. This study explored maternal sensitive factors that are important in the etiology of malnutrition with urban slum setting. The study was conducted among 400 eligible households systematically samples at random. Analysis was based hierarchical regression with principal axis factoring for selective variables. Psychosocial indicators did not have any observable association with nutritional status. Seeking immediate medical attention from the nearest health facility (HSB-1) and Average duration of introducing a child to the first liguid in hours (FP-4) significantly reduced stunting. Clean my hands with running water and soap before feeding a child (FHP-1) significantly reduced stunting among other indicators. HSB-1 somehow increased stunting. Wasting was significantly reduced by HSB-1 but increased by consulting a private doctor to examine a child (HSB-3). Underweight had no association at all with all indicators of maternal factors except at crude odds ratio level where FHP-1and HSB-1 were somewhat associated with underweight. In conclusion, this study revealed that food hygiene practice, health seeking behavior and feeding practice were all significant associates of stunting $(\mathrm{p}<0.05)$. Wasting was only associated with health seeking behaviour $(\mathrm{p}<0.05)$ while underweight had association with food hygiene practice and health seeking behaviour $(\mathrm{p}<0.05)$. However, it is noted that in these factor domains only selected indicator measures exhibited significant associations.
\end{abstract}

Keywords: Maternal, Malnutrition, Nutritional Status, Children Under Five, Slums

\section{Introduction}

Child mortality is directly influenced by poor nutritional status which may also have indirect relationship with maternal sensitive issues. In order to explore on maternal initiated factors that are key in relation to nutritional status, it would be important to first understand the meaning and concept of care in childcare. Some authors define care as the provision of time, attention, and support to meet the physical, mental, and social needs of the growing child and other household members, [1]. This care is reflected in breastfeeding and complementary practices, psychosocial stimulation of children and support for their development; food hygiene practices and care for children during illness, including making attempts to ensure early diagnosis of illness and adoption of appropriate health-seeking practices [1] [2] [3]. These are some of the factors that could possibly be regarded as mother initiated because the mother has full control over them.

Infant feeding practices is a major factor in the etiology of malnutrition. Somehow this component as a key determinant of malnutrition has received little attention in the informal settlement. Some studies have been established that delayed initiation of breastfeeding, deprivation of colostrums and improper complementation are significant risk factors to WAZ and HAZ [4]. The question is whether this outcome is uniform across all settings. The demand and pressure put on caregivers within urban slums to look for daily bread raises 
the question on strict adherence to exclusive breastfeeding and hence possible negative outcome on nutritional status of children within settings. Breastfeeding has proved to generate several benefits for both the infant and the mother. It provides protection against infections in newborns and infants, but highly dependent on initiation, duration and intensity of breastfeeding, and by the age when the child receives supplementary foods and liquids [5][6]. However, it should be noted that breastfeeding alone is not adequate to meet child's nutritional needs after the age of six months. Mothers are encouraged to introduce adequate, safe and high quality complementary foods to the child after six months. Introduction of food other than breast milk depend on several factors include timing and quantity, replacement of breastmilk, energy density/nutrient quality, feeding frequency (in 24 hours) and palatability, feeding style, appetite and contamination /safety [7].

Psychosocial factors may refer to the social and mental support that a mother provides to a child. Some convectional studies have shown strong evidence of the linked between psychosocial care and nutritional status. Inadequate psychosocial care and poor nutrition could be strongly linked [8]. In cases where mothers are passive, less responsive and sensitive to children needs, have low self-esteem and socially isolated, children have exhibited poor nutritional status [9]. Observation of chronically undernourished children and their respective mothers revealed less maternal responsiveness and mutual interaction [10]. These elements of literature therefore confirm strong linkage between psychosocial support and nutritional outcome of children. In normal circumstances informal settlement would be characterized by most mothers who exhibit low self-esteem and would have little response to their children. This informs the need to investigate the overall effect this characteristic would have on nutritional status of children within the informal settlements. Attachment insecurity is a common problem in low income households and closely linked to WAZ children [11]. Psychosocial stimulation has demonstrated quick recovery of severe malnourished children [12].

Food handling practices may have a direct or indirect link to nutritional status and more specific to malnutrition. Some researchers have noticed limited information on food handling practices and how it links to malnutrition in low socio-economic groups in urban setting [13]. Other than environment causes of malnutrition due which are led by unsafe water, poor sanitation and hygiene, poor food-hygiene practices by mother's or caregivers is a critical suspect [14]. A number of factors which may include mother and child's hand washing practice, food preparation including holding time and reheating, use of clean feeding utensil and the cleaning old bottled milk could be drivers to food borne infections and diarrhoea [14][15]. However, these factors have not been linked to nutritional status yet they could be proxy suspects in the etiology of malnutrition. There is need to give more focus on the relationship between food handling practice and nutritional status in order to establish how they contribute to malnutrition within urban informal settlements.
Maternal health seeking behaviour has huge impact on the lives and well-being of their children. This may perhaps be attributed to constant reliance on male head of households to secure access to medical treatment relevant to their children during illness [16]. Many illnesses which affect children have their routes from infections. The infection-malnutrition viscous cycle is evidence [17] and suggests that frequent infections may influence the outcome of malnutrition negatively. This implies that infections have to be treated first before any malnutrition interventions. All these depend on health seeking behaviour of the caregiver. Different categories of health seeking behaviour exist among mothers who caregiver in urban slums. Purchase of drugs from shops, seeking help from private practioners, use of public health facilities and consulting with traditional healers are quick common health seeking behaviours [18]. However, limited studies have attempted to establish the direct link between these categories of health behaviour and nutritional status. Studies that have attempted to establish link between nutritional status and health seeking behaviour demonstrates infections and illnesses as key mediators in the relationship [17]. Malnutrition is a condition that some researchers have classified as those that do not require immediate medical action (Nyamongo and Nyamongo, 2006), yet this could be misleading in the practical critique. This could imply that there is a possibility of direct link between malnutrition and health related action in the disease etiology and response to morbidity. This linkage has not been fully explored.

\section{Materials and Methods}

A cross-sectional analytical design was appropriate for this study. Data was collected among 4000 eligible households listed in Obunga Informal settlement. Key targets were biological mother or surrogate mother of children 6-59 months in a household inclusive of the child.

Sample size was determined according to Fisher et al (1991) formula in Mugenda and Mugenda [19] as follows;

$$
\mathrm{n}=\mathrm{Z}^{2}(\mathrm{pq}) / \mathrm{d}^{2}
$$

Where:

$\mathrm{n}=$ minimum sample size (for population $>10,000$ ) required.

$\mathrm{Z}=$ the standard normal deviate at the required confidence level, (set at 1.96 corresponding to $95 \%$, Confidence level adopted for this study).

$\mathrm{p}=$ population proportion estimated to be stunted in Obunga, which now stands at $41 \%$.

$\mathrm{q}=1-\mathrm{p}$

$\mathrm{d}=$ the degree of accuracy required (was be set at 0.05 if prevalence of malnutrition is not known otherwise the actual prevalence will be used).

Therefore, on substitution:

$=1.96^{2}\left\{0.41(1-0.41) / 0.05^{2}=371.71 \approx 272\right.$ households

However, since the targeted population was 4000 eligible households the final sample size (nf) was adjusted as follows: 


$$
\mathrm{nf}=\mathrm{n} \div\{1+(\mathrm{n} / \mathrm{N})\}
$$

Where; $\mathrm{n} \mathrm{f}=$ desired sample size (when target population is less than 10,000)

$\mathrm{n}=$ desired sample size (when target population is greater than 10,000)

$$
\mathrm{N}=\text { the desired sample size (target population) }
$$

$$
\begin{gathered}
\mathrm{nf}=4000 \div\{1+(4000 / 372)\}=340.42 \approx 341 \text { (plus } 20 \% \\
\text { expected non-response) }
\end{gathered}
$$

Sampling procedure followed a systematic random technique where the first household was chosen by simple random methods than every $10^{\text {th }}$ Household in the listing was selected to participate. Out of $409 \mathrm{HHs}$ only $400 \mathrm{HH}$ finally participated in the study after every $\mathrm{HH}$ was given equal chance of participating in the study.

Dependent variable was child nutritional status. This was operationalized as Anthropometric indices categorized as Height for age z-score (HAZ), Weight for Age z-score (WHZ) and Weight for Height z-score (WAZ). Independent underlying variables focused on maternal initiated factors such as child feeding practices, psychosocial factors, food handling practices and health seeking behaviours.

Descriptive statistics included measures of central tendencies, proportions, use of tables and figures and were used to summarize data. Inferential statistics adopted application of hierarchical regression especially for maternal factors with indicators. This involved application of principle axis factoring for maternal related factors to generate quantifiable Batt-score and subsequent linear regression to establish the relationship between nutritional status and all the independent variables.

\section{Results}

\subsection{Descriptive Statistics of Maternal Factors}

Child feeding practices were measured in terms of exclusive breastfeeding, proportions giving child the first liquid that came from breast, proportion who breastfed, duration of introducing first liquid and duration before weaning. The findings of the study revealed that $79.9 \%$ of households exclusively breastfed (FP 4), 79.5\% introduced their babies to the first liquid from breast (FP 3).

The proportion of caregivers who reported to have breastfed or were breastfeeding stood at $98.7 \%$. Average duration of introducing the first liquid was 2.7 ( \pm 4.6) hours (FP 2). However, this result displays a wider variation across caregivers due to a large standard deviation. The average duration before weaning was $5.7( \pm 1.7)$ months (FP 5). This implies that majority of caregivers were weaning after six months.

Psychosocial factors were measured using fours itemized indicators as informed by literature. Mean score of each item was generated and result shows that most mothers were feeling isolated from peers $(\mu=4.31 \pm 0.96)$. Response to feed needs $(\mu=1.22 \pm 0.58)$, interaction with child at home $(\mu=1.27 \pm 0.58)$ and finding ease to provide food to the child on daily basis ( $\mu=1.84 \pm 0.98$ ) score very low mean reflecting

\begin{tabular}{|c|c|}
\hline Indicator & $\begin{array}{l}\text { Descriptive } \\
\text { statistics }\end{array}$ \\
\hline Feeding practices (categorical) $\{\mathrm{FP}\}$ & Proportion (f) \\
\hline Exclusive breastfeeding-FP-1 & 79.9 \\
\hline $\begin{array}{l}\text { Proportion giving a child the first liquid that come from } \\
\text { the breast-FP-2 }\end{array}$ & 75.5 \\
\hline Proportion who breastfed or is breastfeeding-FP-3 & 98.7 \\
\hline Feeding practice (scale) & Mean (SD) \\
\hline $\begin{array}{l}\text { Average duration of introducing a child to the first liguid } \\
\text { in hours-FP-4 }\end{array}$ & $2.7(4.6)$ \\
\hline Average duration before weaning in months-FP-5 & $5.7(1.7)$ \\
\hline \multicolumn{2}{|l|}{ Psychosocial factors $\{\mathrm{P}\}$} \\
\hline $\begin{array}{l}\text { Immediate response to food needs immediately I sense } \\
\text { that they are hungry }\{\mathrm{P}-1\}\end{array}$ & $1.44(0.58)$ \\
\hline $\begin{array}{l}\text { Interact with the child quite at home to make him/her } \\
\text { happy. }\{\mathrm{P}-2\}\end{array}$ & $1.27(0.58)$ \\
\hline Ease of providing food to a child on daily basis $\{\mathrm{P}-3\}$ & $1.84(0.98)$ \\
\hline Feeling of isolation from peers $\{\mathrm{P}-4\}$ & $4.31(0.96)$ \\
\hline \multicolumn{2}{|l|}{ Food handling practice $\{\mathrm{FHP}\}$} \\
\hline $\begin{array}{l}\text { Clean my hands with running water and soap before } \\
\text { feeding a child }\{\text { FHP- } 1\}\end{array}$ & $1.45(0.59)$ \\
\hline $\begin{array}{l}\text { Wash all the utensils for feeding a child with clean water } \\
\{\text { FHP-2 }\}\end{array}$ & $1.26(0.58)$ \\
\hline Clean the nipple before breastfeeding $\{$ FHP- 3$\}$ & $2.77(1.5)$ \\
\hline $\begin{array}{l}\text { Storing food in a well ventilated room and covered } \\
\text { container for later serving }\{\text { FHP- } 4\}\end{array}$ & $1.44(0.62)$ \\
\hline $\begin{array}{l}\text { Washing a child's hand with a running water and soap } \\
\text { before feeding }\{\text { FHP-5 }\}\end{array}$ & $1.51(0.7)$ \\
\hline $\begin{array}{l}\text { Re-heating food remains at appropriate holding time } \\
\text { before serving }\{\text { FHP- } 6\}\end{array}$ & $1.41(0.72)$ \\
\hline \multicolumn{2}{|l|}{ Health Seeking Bhaviour $\{\mathrm{HSB}\}$} \\
\hline $\begin{array}{l}\text { Seeking immediate medical attention from the nearest } \\
\text { health facility }\{\text { HSB- } 1\}\end{array}$ & $1.51(0.7)$ \\
\hline Buying drugs from herbalist and give him/her. $\{$ HSB-1 $\}$ & $3.40(1.5)$ \\
\hline Consulting to get medicine from herbalist. \{HSB-2\} & $3.81(1.38)$ \\
\hline Consulting a private doctor to examine a child $\{$ HSB-3\} & $4.47(2.67)$ \\
\hline Praying for the child to get well. $\{$ HSB- 4$\}$ & $1.94(1.35)$ \\
\hline $\begin{array}{l}\text { Consistent adherence to the immunization schedules } \\
\{\text { HSB-5\} }\end{array}$ & $1.25(0.72)$ \\
\hline
\end{tabular}
that most mother did not approve of such actions within the urban setting.

Table 1. Descriptive statistics of maternal factors.

Smaller means score were also recorded for the six food handling practice measures. Cleaning hand with a soap and running water before feeding a child $(\mu=1.45 \pm 0.59)$, washing utensils before feeding a child $(\mu=1.26 \pm 0.58)$, Clean the nipple before breastfeeding ( $\mu=2.77 \pm 1.5)$, Storing food in a well ventilated room and covered container for later serving ( $\mu=1.44 \pm 0.62$ ), Washing a child's hand with a running water and soap before feeding ( $\mu=1.51 \pm 0.7)$, and Re-heating food remains at appropriate holding time before serving $(\mu=1.41 \pm 0.71)$ all showed minimal practice among the caregivers.

Within health seeking behaviour, seeking immediate medical attention from the nearest health facility $(\mu=1.51 \pm 0.7)$ registered lower perceived practice. Buying drugs from herbalist and give him/her $(\mu=3.4 \pm 1.5)$, Consulting to get medicine from herbalist $(\mu=3.81 \pm 1.38)$, Consulting a private doctor to examine a child $(\mu=4.47 \pm 2.67)$ 
registered high practice level. Praying for the child to get well $(\mu=1.94 \pm 1.35)$ and consistent adherence to the immunization schedules $(\mu=1.25 \pm 0.72)$ also recoded very low level practice in the distribution.

\subsection{Psychosocial Actors}

Four indicators of psychosocial factor subjected to principal axis, loaded into one single factor labeled "psychosocial factor" in the context of child feeding support which accounted for $25.4 \%$ of cumulative variance of all measurement items. The single construct only identified "response to child food needs" (communality=0.548) and "interaction with the child" (communality $=0.781$ ) as the most significant measures of psychosocial factor extracted at a minimum of 0.40 communality.

Table 2. Distribution of caregivers by performance psychosocial factors.

\begin{tabular}{ll}
\hline Indicator measures & $\begin{array}{l}\text { Psychosocial } \\
\text { Factor }\end{array}$ \\
\hline $\begin{array}{l}\text { Caregiver respond to child food needs immediately } \\
\text { he/she sense child hunger }\end{array}$ & .548 \\
$\begin{array}{l}\text { Caregiver I interact with child quite often at home to } \\
\text { make him/her happy. }\end{array}$ & .781 \\
$\begin{array}{l}\text { Caregiver finding it easy to provide food to child on } \\
\text { daily basis }\end{array}$ & ๆ \\
$\begin{array}{l}\text { Caregiver feeling isolated by my peers within the } \\
\text { premise }\end{array}$ & ๆ \\
IBelow variance/communality magnitude of 0.40 & \\
\hline
\end{tabular}

\subsection{Health Seeking Behavior}

Table 3. Distribution of caregivers by performance health seeking behaviour factors.

\begin{tabular}{|c|c|c|c|}
\hline \multirow{2}{*}{$\begin{array}{l}\text { Health seeking behavior measures } \\
\text { Factor }\end{array}$} & \multicolumn{3}{|c|}{$\begin{array}{l}\text { Health Seeking } \\
\text { Behaviour }\end{array}$} \\
\hline & HSB 1 & HSB 2 & HSB 3 \\
\hline $\begin{array}{l}\text { Caregiver seeking immediate medical attention } \\
\text { from the nearest health facility anytime a child } \\
\text { gets ill. }\end{array}$ & ฯ & .601 & ฯ \\
\hline $\begin{array}{l}\text { Caregiver buys drugs from herbalist and give } \\
\text { child when ill }\end{array}$ & .657 & ฯ & ฯ \\
\hline $\begin{array}{l}\text { Caregiver consults to get medicine from } \\
\text { herbalists as soon as a child gets ill. }\end{array}$ & .661 & ฯ & ฯ \\
\hline $\begin{array}{l}\text { Caregiver calls a private doctor to examine } \\
\text { him/her as soon as a child gets ill. }\end{array}$ & ฯ & $*$ & .471 \\
\hline $\begin{array}{l}\text { Caregiver prays for a child anytime a child gets } \\
\text { ill. }\end{array}$ & ฯ & .590 & ๆ \\
\hline $\begin{array}{l}\text { Caregiver adhere to the immunization schedules } \\
\text { for her child }\end{array}$ & ฯ & ฯ & ฯ \\
\hline I Below variance/communality magnitude of 0.40 & & & \\
\hline
\end{tabular}

Principal axis factoring apparently identified three health seeking behavior categories labeled as "HSB-1", "HSB-2" and "HSB-3". These cumulatively explain up to $35.5 \%$ of the variance on health seeking behavior. HBS-1 was characterized by "purchase of drugs from herbalists" and "consulting the herbalist to get drugs" with coefficients of 0.657 and 0.661 respectively (communalities). This component of HBS-1 accounted for $16.6 \%$ of health seeking behavior. HBS-2 was characterized by "seeking of medical attention immediately a child gets ill" and "praying for a child" with coefficient of 0.60 and 0.59 respectively. This component of HSB-2 accounted for $12.8 \%$ of health seeking behavior. HBS- 2 was characterized by "consultation with a private doctor" with a coefficient value of 0.471 and accountability of $6.12 \%$ of health seeking behavior. These results therefore revealed that HBS-1 was the best measure of health seeking behavior followed by HBS-2 and HBS- 3 in that order.

\subsection{Food Handling Practices}

The findings further explored food handling practices to identify key item measures characterizing the caregiver perceptions. Principal axis factoring established two important categories of food handling practices. These categories of food handling practices were labeled FHP-1 and FHP-2 both accounting for $48.6 \%$ of the total variance of food handing practice factor.

FHP-1 was characterized by "cleaning hand with running water and soap before feeding a child" (communality $=0.512$ ) "washing utensils for child feeding with water and soap before serving food" (communality $=0.887$ ) "storing child food in well ventilated room and covered container" (communality $=0.65$ ) and "cleaning a child hand with running water and soap" (communality=0.446) higher coefficient represented the best measure which isolated "washing of utensils for feeding a child with water and soap before serving" as best item measure. It is worth noting that this component accounted for $29.5 \%$ of food handling practice.

FHP-2 was characterized by "cleaning hand with running water and soap before feeding a child" (communality=0.446), "storing feeding food in well ventilated room and covered container" (communality $=0.458$ ), "cleaning child hand with running water and soap before serving food" (communality $=0.647$ )" and "ensuring that food remains are appropriately re-heat before served to a child (communality $=0.559$ ).

Table 4. Distribution of caregivers by performance food handling practice factors.

\begin{tabular}{|c|c|c|}
\hline \multirow[t]{2}{*}{ Hygiene measure } & \multicolumn{2}{|c|}{$\begin{array}{l}\text { Food Hygiene } \\
\text { Practice factor }\end{array}$} \\
\hline & FHP 1 & FHP 2 \\
\hline $\begin{array}{l}\text { Caregiver cleaning hands with running water and } \\
\text { soap before feeding a child }\end{array}$ & .512 & .446 \\
\hline $\begin{array}{l}\text { Caregiver washing utensils for feeding with clean } \\
\text { water and soap before serving food }\end{array}$ & .887 & ๆ \\
\hline Caregiver cleaning the nipple before breastfeeding. & ฯ & ๆ \\
\hline $\begin{array}{l}\text { Caregiver storing child food in a well ventilated room } \\
\text { and covered container if they are to be served latter. }\end{array}$ & 650 & .458 \\
\hline $\begin{array}{l}\text { Caregiver cleaning child and hand washing a child } \\
\text { with a running water and soap before serving food }\end{array}$ & .446 & .647 \\
\hline $\begin{array}{l}\text { Caregivers ensuring that any food that remains and is } \\
\text { served to child is well re-heat with appropriate } \\
\text { holding time. } \\
\text { I Below variance/communality magnitude of } 0.40\end{array}$ & ฯ & .559 \\
\hline
\end{tabular}

\subsection{Influence of Maternal Factors on Nutritional Status}

Based on the initial binary coding applied for WAZ is previous sections, the association between stunting and maternal factors under investigation was performed using 
binary logistic regression. An assessment based on Adjusted odds ratios at $95 \% \mathrm{C}$. $\mathrm{L}$ revealed significant association between food handling practice (FHP-1) and stunting (Adjusted odds ratio $=0.76, \mathrm{Cl}=0.585-0.988, \mathrm{p}<0.05$ ). This implies that 1 unit increase in PHP-1 was more likely to decrease stunting by 0.76 times. At crude level, HSB-2 was significantly associated with stunting. However, after adjustments there appeared to be no significant association.

Table 5. Maternal factors associated with stunting based on crude odds ratio and adjusted odds ratio at $95 \%$ level of confidence.

\begin{tabular}{|c|c|c|c|c|}
\hline Variable & Crude OR & $95 \%$ C. I & Adjusted OR & $95 \%$ C. I \\
\hline \multicolumn{5}{|l|}{ Stunting } \\
\hline $\mathrm{P}$ & 1.034 & $.877-1.22$ & 1.243 & $.996-1.55$ \\
\hline FHP-1 & $0.812 *$ & $.673-.979$ & $.760 *$ & $.585-.988$ \\
\hline FHP-2 & 0.886 & $.751-1.045$ & .865 & $.680-1.102$ \\
\hline HSB-1 & 1.158 & $.987-1.359$ & $1.248 *$ & $1.012-1.539$ \\
\hline HSB-2 & $.798 *$ & $.683-.931$ & .962 & $.771-1.2$ \\
\hline HSB-3 & .886 & $.744-1.056$ & .902 & $.746-1.091$ \\
\hline FP-1 & .255 & $.026-2.462$ & .214 & $.022-2.133$ \\
\hline FP-2 & .977 & $.933-1.023$ & .979 & $.934-1.025$ \\
\hline FP-3 & 1.494 & $.866-2.577$ & 1.655 & $.865-3.167$ \\
\hline FP-4 & $.395 *$ & $.197-.794$ & $.459 *$ & $.221-.953$ \\
\hline FP-5 & .961 & $.824-1.121$ & .985 & $.841-1.155$ \\
\hline \multicolumn{5}{|l|}{ Wasting } \\
\hline $\mathrm{P}$ & .983 & $.768-1.258$ & 1.005 & $.739-1.367$ \\
\hline FHP-1 & 1.028 & $.804-1.315$ & 1.051 & $.731-1.512$ \\
\hline FHP-2 & .805 & $.621-1.043$ & .844 & $.580-1.229$ \\
\hline HSB-1 & $.662 *$ & $.531-.827$ & $.682 *$ & $.510-.911$ \\
\hline HSB-2 & 1.031 & $.820-1.295$ & 1.032 & $.737-1.445$ \\
\hline HSB-3 & $1.250 *$ & $1.023-1.528$ & $1.258 *$ & $1.015-1.56$ \\
\hline FP-1 & 3.596 & $.526-24.603$ & 3.656 & $.482-27.703$ \\
\hline FP-2 & 1.034 & $.984-1.088$ & 1.042 & $.990-1.097$ \\
\hline FP-3 & .984 & $.466-2.076$ & .628 & $.262-1.506$ \\
\hline FP-4 & 1.572 & $.628-3.932$ & 1.064 & $.408-2.778$ \\
\hline FP-5 & 1.007 & $.812-1.25$ & .988 & $.792-1.233$ \\
\hline \multicolumn{5}{|c|}{ Underweight } \\
\hline $\mathrm{P}$ & .815 & $.614-1.083$ & .992 & $.718-1.370$ \\
\hline FHP-1 & .904 & $.709-1.152$ & 1.003 & $.696-1.444$ \\
\hline FHP-2 & $.622 *$ & $.469-.824$ & .691 & $.466-1.025$ \\
\hline HSB-1 & $.715^{*}$ & $.580-.882$ & .757 & $.569-1.006$ \\
\hline HSB-2 & .803 & $.632-1.020$ & .961 & $.681-1.356$ \\
\hline HSB-3 & .935 & $.759-1.152$ & .974 & $.783-1.212$ \\
\hline FP-1 & 1.111 & $.113-10.881$ & .653 & $.050-8.499$ \\
\hline FP-2 & 1.025 & $.975-1.079$ & 1.028 & $.975-1.084$ \\
\hline FP-3 & 1.649 & $.830-3.274$ & .916 & $.407-2.065$ \\
\hline FP-4 & 1.165 & $.471-2.878$ & 1.128 & $.451-2.823$ \\
\hline FP-5 & 1.058 & $.865-1.295$ & 1.078 & $.886-1.312$ \\
\hline
\end{tabular}

Feeding practice (FP-4) was significantly associated with stunting (Adjusted odds ratio $=0.459$, CI $=0.221-0.953$, $\mathrm{P}<0.05)$. This implies that I unit increase in $\mathrm{P}-4$ was more likely to decrease stunting by 0.459 times. Material factors including psychosocial PHP-1 HSB-1, HSB-3, FP-1, FP2, EP5 had no significant association with stunting $((\mathrm{P}<0.05)$, and therefore would not be considered important in the stunting linear equation.

Two factors emerged as significant associates of wasting which included HSB-1 and HSB-3. HSB-1 was inversely associated with wasting (Adjusted odds ratio $=0.682$, $\mathrm{C} 1=0.510-0.911, \mathrm{PC} 0-05)$. This implies that 1 unit increase in HSB-1 was more likely to decrease wasting by 0.682 times. On the other hand HSB-3 was directly associated with wasting (Adjusted odds ratio $=1.258, \mathrm{C} 1=1.015-1.56, \mathrm{P}$ $<0.05$ ). This implies that 1 unit in HSB-3 was more likely to increase wasting by 1.258 times.

Other maternal factors such as P, PHP-1, PHP-2, HSB-2 FP (1-5) were not significantly associated with wasting. This outcome ruled out these components of material factors from being associated with wasting.

Finally all the maternal factors were linked to underweight. Similarly, underweight was coded using binary format as was the case in previous sections. From the table displayed, only two factors attempted to be weakly associated with wasting. FHP-2 was significantly associated with underweight at crude level (crude odds ratio $=0.622, \mathrm{CI}=0.469-0.824, \mathrm{P}<0-05$ ). However this association did not hold after Adjustments were made. HSB-1 was also determined to be associated with underweight at crude level. (Crude odds ratio $=0.715, \mathrm{C} 1=$ $0.58-0.882, \mathrm{P}<0.05)$. Again this association did not hold after adjusting of odds ratios. Both factors at crude level showed inverse association with underweight implying that 1 unit of each were more likely to decrease underweight. All others factors under investigations had no significant association and somehow rule out in this relationship.

\section{Discussion}

Maternal factors focused on hygiene produces, breast feeding practices and health seeking behaviours. Apparently, the study revealed that some of the health seeking indicators had significant Breast feeding practices had no influence at all across all the indicators. Food handling practice (FHP-1) characterized by correct caregivers hand washing, method utensil washing before feeding, proper storage of food and cleaning child hand significantly predicted WHZ.

Comparing these results with previous literature the outcome of breastfeeding somehow revealed contrasting results with a study conducted by Kumar et al. [4]. It could be sound to argue that Kumar et al. were more on risk assessment of malpractice in breastfeeding rather than linear and direct predictability. However, the decreasing power of breast feeding indicators were evidence on HAZ WHZ and WAZ showing inverse effect of correct child feeding practices on nutritional status.

Nyamonjo and Nyamongo [18] identify different categories of health seeking behaviours. Likewise this study revealed significant and contribution of health seeking behaviours on HAZ, WHZ and WAZ seeking consultation for herbalist and purchasing herbal medicine emerged the key determinates of HAZ and WHZ. Interesting enough, the more a caregiver consulted with herbalist the less risk was HAZ and WHZ levels. A mother who is willing and able to seek advice on how to go about child illness has higher chances of getting help to prevent further injuries for her child. In this study consulting herbalist for example demonstrated efforts of making attempt to find treatment for a child illness showing a positive improvement on HAZ and WHZ. In many cases child illness would increase prevalence of HAZ WHZ and WAZ if not addressed in time. Evidence of the 
signification influence of seeking a private doctor consultation confirms the school of thought that care givers would attempt to break the infection-malnutrition cycle (Katona and Katona, 2008) as a self initiated effort.

Food handling practice category 1 (FHP-1) emerged as the only significant predictor of a nutritional status index mainly WHZ. This component of maternal factor did not predict other indices of nutritional status. Taking a critical review a previous study Takanoshi et al. [13] established a link between food handling practices are malnutrition from low-economic groups in urban setting. Even though this study only confirmed this linkage in a similar pattern based on WHZ, it gave a hint of role of food handling practices. These results both concur with Rina et al. [14] and Ejenot et al. [15]. The letter too studies reveal some significant proxy influence on nutrition status. In this current study, a direct influence seems to emerge for the case of WHZ as nutritional status idea.

Psychosocial factors did not have significant influence on HAZ, WHZ and WAZ. While Olson, et al. [8], Kerr and Bogus [9] and Graves [10] all emphasize on strong linkage between psychosocial factors and nutritional status, this study revealed contrary results among urban slum households. In the previous studies low self esteem, socio-isolation and maternal responsiveness are key determinants of nutritional status. In this category of factors no significant influence was noticed considering all nutritional status indices. Probably what could be deduced is the non-existence of direct influence, and this may call for a test of proxy effect rather than direct effect on nutritional status.

\section{Conclusion}

In conclusion, this study revealed that food hygiene practice, health seeking behavior and feeding practice were all significant associates of stunting $(\mathrm{p}<0.05)$. Wasting was only associated with health seeking behaviour $(p<0.05)$ while underweight had association with food hygiene practice and health seeking behaviour $(\mathrm{p}<0.05)$. However, it is noted that in these factor domains only selected indicator measures exhibited significant associations.

\section{References}

[1] Engle, P. L., Menon, P., \& Haddad, L. (1997). Care and Nutrition: Concepts and Measurement. International Food Policy Research Institute (IFPRI), Washington, D. C.

[2] Rahman, A., Patel, V., Maselko, J., \& Kirkwood, B. (2008). The neglected ' $m$ ' in MCH programmes-why mental health of mothers is important for child nutrition. Tropical Medicine and International Health, 13 (4), 579-583.

[3] Ramji, S. (2009). Impact of infant and young child feeding \& caring practices on nutritional status \& health. Indian Journal of Medical Research 130: 624-626.

[4] Kumar, D. Agarwal, N. \& Swani, H. M. (2006). Sociodemographic correlates of breast-feeding in urban slums of Chandigash. Indian Journal of Science, 60: 461-466.
[5] Dornelles, T. L. C., Jefferson, P. P., \& Paulo, J. C. M. (2007). Nutritional Status, Breastfeeding, and Evolution of Infants with Acute Viral Bronchiolitis. Journal of Health Population and Nutrition 25 (3), 336-343.

[6] Chakrabarty, S., Ghosh, R., \& Bharati, P. (2005). Breastfeeding practices and Nutritional Status of Preschool Children among the Shabar Tribal Community in Orissa, India. Paper presented at the Proceedings of National Symposium on Tribal Health.

[7] Mahgoub, S. E. O., Nnyepi, M. \& Bandeke, T. (2006). Factors affecting prevalence of malnutrition among children under three years of age in Botswana. African Journal of Food and Development, 6: 1-15.

[8] Olson, S. L., Bayales, I., \& Bates, J. E. (1986). Mother-child interactions and children's speech progress: a longitudinal study of the first two years. Merril-Palmer $Q ; 32: 1-20$.

[9] Kerr, M., Bogues, J. \& Kerr, D. (1978). Psychosocial functioning of mothers of malnourished children. Pediatrics; 62: 77884 .

[10] Graves, P. (1976). Nutrition, infant behavior, and maternal characteristics: a pilot study in West Bengal, India. American Journal of Clinical Nutrition; 29: 305-309.

[11] Valenzuela, M (1990). Attachment in chronically WAZ young children. Child Development; 61: 1984-96.

[12] Nahar, B., Hamadani, J. D. Ahmed, T., Tofail, F., Rahman, A. Huda, S. N. \& Grantham-McGregor, S. M (2009). Effects of psychosocial stimulation on growth and development of severely malnourished children in a nutrition unit in Bangladesh. European Journal of Clinical Nutrition; 63: 725731.

[13] Takanashi, K., Chonan, Y., Quyen, D. T., Khan, N. C., Poudel, K. C., and Jimba, M (2009). Survey of Food-hygiene practices at home and childhood diarrhoea in Hanoi, Viet Nam. Journal of Health Population and Nutrition; 27 (5): 602-611.

[14] Rina, A., Tirta, P. S., Soemilah, S., Ingeborg, M. J. Edith, J. M. F. \& Frans. J. K. (2013). Association of food-hygiene practices and diarrhea prevalence among Indonesian young children from low socioeconomic urban areas; BMC Public Health, 13: 977.

[15] Ejemot, R. I., Ehiri, J. E., Meremikwu, M. M., \& Critchley, J. A (2008). Hand washing for preventing diarrhoea. Cochrane Database Systems Review 1, CD004265.

[16] Rahman, S. A. (2000). Utilization of Primary Health Care Services in Rural Bangladesh: the population and provider perspectives Unpublished $\mathrm{PhD}$ Thesis, London School of Hygiene and Tropical Medicine, University of London.

[17] Katona, P. and Katona, A. J. (2008). The Interaction between Nutrition and Infection. Clinical Infectious Diseases; 46 (10): 1582-1588.

[18] Nyamongo, AM., and Nyamongo, K. N (2006). Health Seeking Behaviour of Mothers of Under-Five-Year-Old Children in the Slum Communities of Nairobi, Kenya. Anthropology \& Medicine, 13 (1): 25-40.

[19] Mugenda, O. M. and Mugenda, A. G. (1999) Research Methods: Quantitative and Qualitative Approaches. Acts Press, Nairobi. 